palsy will be identified at 1 year, and it will be interesting to see how many of this group of infants with perinatal problems emerge with lesser degrees of cerebral palsy when they are older.

Of the 536 babies studied, four died from the sudden infant death syndrome. Three of these were of low birth weight $(<2500 \mathrm{~g})$ and one had Down's syndrome. Our district records indicate that 13 babies born in 1975 died in their first year from this cause out of just over 5000 live births. Therefore about one-third of the cot deaths occurred in our high-risk group.

Conclusions-The overall fall in perinatal mortality in Southampton and district has therefore been similar to the national average and has been caused largely by a fall in the stillbirth rate. In 1976 it was also helped by a fall in the death rate in the first week after birth. This occurred in spite of a changing surgical attitude to the active management of neural tube defects. Low birth weight and preterm delivery were not the main causes of major handicap detected at one year, as two-thirds of the major handicaps arose from congenital abnormalities.

\section{References}

1 Stewart, A L, and Reynolds, E O R, Pediatrics, 1974, 54, 724.

2 Fitzhardinge, P M, and Ramsey, M, Developmental Medicine and Child Neurology, 1973, 15, 447.

${ }^{3}$ Francis-Williams, J, and Davies, P A, Developmental Medicine and Child Neurology, 1974, 16, 709 .

${ }^{4}$ Davies, P A, and Tizard, J P M, Developmental Medicine and Child Neurology, 1975, 17, 3 .

${ }^{5}$ Stewart, A L, et al, Archives of Disease in Childhood, 1977, 52, 97.

${ }^{6}$ Williamson, E M, fournal of Medical Genetics, 1965, 2, 16.

${ }^{7}$ Hutchinson, J H, Practical Paediatric Problems. 4th edn. London, LloydLuke, 1975.

${ }^{8}$ Woods, A E, Developmental Medicine and Child Neurology, 1976, 18, 394.

(Accepted 2 December 1977)

\title{
Atopy and immunoglobulin E concentrations in Hodgkin's disease and other lymphomas
}

\author{
P L AMLOT, L A GREEN
}

to some but not all type I allergic manifestations-for example, hay fever, seasonal rhinitis, eczema, and asthma. With one exception, no valid study so far has shown any differences in serum IgE concentrations between people with cancer and those without. ${ }^{8} 9$ The one exception showed high concentrations in 11 out of 19 patients with Hodgkin's disease (HD). ${ }^{10}$ The high incidence of atopy (six of the 19 patients) in this small group was unusual, however, and the results could not be confirmed in a retrospective study by Steinberg et al. ${ }^{11}$

Our study aimed to determine serum IgE concentrations in patients with active HD and other lymphomas, and to assess the relevance of atopic history, patient's clinical state, and treatment to the concentrations. Atopic patients had a significantly lower incidence night sweats, fever, and weight loss, and treatment had no significant lasting effect on their IgE concentrations. In the non-atopic group there was a striking correlation between high IgE concentrations and a histological appearance of nodular sclerosis, particularly in the presence of night sweats, fever, and weight loss. Successful treatment in the non-atopic group led to a noticeable fall in IgE concentrations, in most cases to normal, though on relapse of the disease they rose again.

\section{Introduction}

Early observations that atopic illness is less common in patients with cancer than in the normal population suggested that atopy might have a protective role in oncogenesis, ${ }^{1-3}$ but subsequent controlled studies showed comparable incidences of atopy in people with and without cancer. ${ }^{4-6}$ With the identification of immunoglobulin $\mathrm{E}(\mathrm{IgE})$ as the major class of reaginic antibody : the basic type I allergic response could be studied direct without relying on a history of atopy to indicate a genetic predisposition

Department of Medicine, Guy's Hospital Medical School, London SE1 9RT

P L AMLOT, MB, MRCP, lecturer in medicine

L A GREEN, DAS(AUST), technician

\section{Subjects and methods}

We studied 115 patients with active HD. Ninety were studied before treatment, and the remaining 25 were in relapse 10-28 months after undergoing radiotherapy as the sole treatment. The disease was staged by means of the Ann Arbor classification, ${ }^{12}$ and histology accorded with the Rye modification of Lukes and Butler's classification. ${ }^{13}$ Radiotherapy for HD was given by "mantle" or "inverted Y" fields, 3500-4000 rads being delivered over four to five weeks. ${ }^{14}$ Quadruple chemotherapy was given in some cases. ${ }^{15}$

Sixty-eight patients with other lymphomas were also studied, all before treatment. Fifty-three had lymphocytic lymphomas (22 well-differentiated, nine chronic lymphatic leukaemic, and 22 poorly differentiated types); eight had histiocytic lymphomas; four had mixed histiocytic and lymphocytic lymphomas; one had reticuloendotheliosis; one had a Burkitt-like lymphoma; and one had angioimmunoblastic lymphadenopathy. One hundred and eighty laboratory personnel, blood donors, and dental outpatients served as controls.

Patients and controls were regarded as atopic if they had a definite history of atopic symptoms, such as asthma, hay fever, perennial rhinitis, urticaria, and eczema. A history of drug reaction was not counted as an atopic manifestation. To ascertain that an atopic background had not been overlooked, patients with IgE concentrations above normal were prick-tested for immediate hypersensitive reactions to a large battery of common allergens-namely, pollens; yeasts and fungi; foods; furs, feathers, and danders; and house-dust mites. Twenty of the controls were found to be atopic; a further 57 
subjects included in the atopic control group were obtained from patients attending Guy's Hospital allergy clinic whose IgE concentrations had been measured.

For $I g E$ assay we used a slightly modified version of the liquid-phase double-antibody radioimmunoassay described by Nye et al. ${ }^{16}$ One part of each sample and standard (IgE research reference standard 68/341) was diluted in two parts of fetal calf serum, and $100 \mu \mathrm{l}$ aliquots were incubated for 16 hours at room temperature with $100 \mu l$ of ${ }^{125} \mathrm{I}-\mathrm{IgE}$ (Pharmacia, Uppsala, Sweden) and $100 \mu \mathrm{l}$ of a 1 in 60000 dilution of anti-IgE (Hoechst Ltd, Middlesex). To precipitate bound IgE we added a second antibody consisting of $50 \mu$ l of a 1 in 130 dilution of normal rabbit serum, followed by a 1 in 17 dilution of donkey anti-rabbit antiserum (Burroughs Wellcome, Kent). After a further 16 hours' incubation the precipitates were washed and counted in an LKB gamma counter. Means of paired sample values were read against the standard inhibition curve. Results are expressed as $\mathrm{U} / \mathrm{ml}$ $(1 \mathrm{U} / \mathrm{ml}$ is approximately $2 \mathrm{ng} / \mathrm{ml}$ ).

For statistical analysis we used a technique allowing multiple comparisons to be made against a single control by use of Dunnett's tables. ${ }^{17}$ Occasions when other statistical techniques were used are indicated in the text. Since people with atopy have higher serum IgE concentrations ${ }^{7}$ than those without, the two groups were analysed separately. Serum IgE concentrations do not have a normal distribution, so logarithmic transformation, which approximates to normality, was used for analysis. Results are expressed as geometric means (GMs).

\section{Results and comment}

\section{INFLUENCE OF ATOPY ON IGE CONCENTRATION}

Serum IgE concentrations were distinctly higher in atopic than non-atopic controls. Table I shows the difference in GM IgE concentrations between atopic and non-atopic subjects, and this difference was the reason for analysing these groups separately in HD and the other types of lymphoma.

TABLE I-Serum IgE concentrations in untreated patients with Hodgkin's disease, patients with other lymphomas, and healthy controls

\begin{tabular}{|c|c|c|}
\hline \multirow[t]{2}{*}{ Group } & \multicolumn{2}{|c|}{$\begin{array}{l}\text { Geometric mean } \underset{(\mathrm{IgE} \text { concentrations (range) }}{(\mathrm{ml})} \\
.\end{array}$} \\
\hline & Non-atopic subjects & Atopic subjects \\
\hline $\begin{array}{l}\text { Hodgkin's disease .. } \\
\text { Other lymphomas .. } \\
\text { Healthy controls } \quad .\end{array}$ & $\begin{array}{l}55^{*}(0-200000)(n=78) \\
16(0-4500)(n=61) \\
13(0-150)(n=160)\end{array}$ & $\begin{array}{c}453+(91-23000)(n=12) \\
30 \pm(7-160)(n=7) \\
181^{+}(16-3200)(n=77)\end{array}$ \\
\hline
\end{tabular}

*P $<0.01$ compared with non-atopic controls.

$+\mathrm{P}<0.05$ compared with atopic controls.

Serum IgE concentrations were significantly higher in both atopic and non-atopic patients with HD than in the respective controls (table I). A third of the non-atopic patients with HD had concentrations above the normal range $(0-150 \mathrm{U} / \mathrm{ml}$,) and many had concentrations much higher than those seen in the atopic population.

The GM IgE concentration in non-atopic patients with other lymphomas did not differ appreciably from normal, but atopic patients had significantly decreased concentrations when compared with atopic controls. Only one patient had a noticeably high IgE concentration $(4500 \mathrm{U} / \mathrm{ml})$, and this may have been related to epidermolysis bullosa, which had been present since childhood.

Atopy occurred in $15(13.0 \%)$ of the 115 patients with HD and $7(10.3 \%)$ of the 68 with other lymphomas. This incidence was similar to that in the controls $(20(11.1 \%)$ out of 180$)$ and that of $10-15 \%$ reported for the atopic symptoms stated. ${ }^{6}$ Atopic patients with $\mathrm{HD}$ reacted to prick tests with various common allergens. None of the non-atopic patients with HD and increased IgE concentrations responded to the same prick tests, though they showed a normal weal and flare response to histamine.

\section{CLINICOPATHOLOGICAL CORRELATIONS OF IGE CONCENTRATIONS IN HD}

IgE concentrations were analysed in terms of the important prognostic features in HD and the occurrence of pruritus. From analysis by stage of spread and histological type the 15 atopic patients with $\mathrm{HD}$ were too few for meaningful analysis and they were therefore excluded.

Stage of disease spread made no significant difference to the GM IgE concentrations, which were $27 \mathrm{U} / \mathrm{ml}$ in stage I (12 patients) $63 \mathrm{U} / \mathrm{ml}$ in stage II (12 patients), $98 \mathrm{U} / \mathrm{ml}$ in stage III (45 patients), and $52 \mathrm{U} / \mathrm{ml}$ in stage IV (31 patients).

Histological subtypes (see table II)-There were significant increases 0 in GM IgE concentrations in only the nodular sclerosis and mixed.. cellularity subtypes of $\mathrm{HD}$. The lymphocyte-predominant and lym $\overrightarrow{\mathrm{c}}$ phocyte-depleted subtypes had normal IgE concentrations.

TABLE II-Serum IgE concentrations in histological subtypes of Hodgkin's $\frac{\omega}{\sqrt{D}}$ disease

\begin{tabular}{|c|c|c|c|c|}
\hline \multirow{2}{*}{\multicolumn{2}{|c|}{ Histological subtype }} & \multicolumn{3}{|c|}{ Geometric mean $\mathrm{IgE}$ concentrations $(\mathrm{U} / \mathrm{ml})$} \\
\hline & & $\begin{array}{l}\text { Whole } \\
\text { group }\end{array}$ & $\begin{array}{c}\text { Asymptomatic } \\
\text { patients }\end{array}$ & $\begin{array}{c}\text { Symptomatic } \\
\text { patients }\end{array}$ \\
\hline $\begin{array}{l}\text { Lymphocyte-predominant } \\
\text { Nodular sclerosis } \quad . . \\
\text { Mixed cellularity } \\
\text { Lymphocyte-depleted }\end{array}$ & $\begin{array}{l}\cdots \\
\cdots \\
\cdots\end{array}$ & $\begin{array}{c}38(n=8) \\
222^{*}(n=32) \\
48^{*}(n=44) \\
17(n=16)\end{array}$ & $\begin{array}{l}38(n=8) \\
68^{*}(n=18) \\
31(n=22) \\
4(n=2)\end{array}$ & $\begin{array}{c}877^{*}(n=14) \\
75^{*}(n=22) \\
20(n=14)\end{array}$ \\
\hline
\end{tabular}

*P $<0.01$ compared with non-atopic controls.

Symptoms (unexplained night sweats, fever, and weight loss)-0 IgE concentrations were significantly higher in symptomatic $\left(G^{\supset}\right.$ $103 \mathrm{U} / \mathrm{ml}$ ) than asymptomatic patients (GM $41 \mathrm{U} / \mathrm{ml} ; \mathrm{P}<0.05$, Student's $t$ test), but this may largely have been due to the increase ${ }_{\mathbb{D}}^{T}$ in IgE concentrations in symptomatic patients with nodular sclerosis (table II). Nodular sclerosis was the only subtype in which there was a significant difference in $\operatorname{IgE}$ concentrations between symptomatic and asymptomatic patients $(P<0.0025$, Student's $t$ test). Atopic patients had a noticeably and significantly lower incidence of symptoms than the non-atopic patients: only one of the 15 atopic patients. had symptoms, compared with 50 of the 100 non-atopic patients $(\mathrm{P}<0.005$, Fisher's exact test $)$.

Pruritus-Seventeen of the 100 non-atopic patients suffered from pruritus at some time during their illness, and five of these patients had cutaneous lesions attributable to scratching. IgE concentrations $\frac{2}{\Phi}$

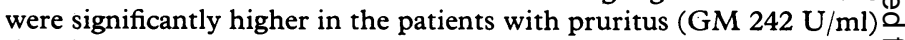
than in the others (GM $50 \mathrm{U} / \mathrm{ml} ; \mathrm{P}<0 \cdot 01$, Student's $t$ test). Twelve $\overrightarrow{\vec{B}}$ of the patients with pruritus had nodular sclerosis. Pruritus also 3 occurred in eight of the 15 atopic patients. Two of these had atopic eczema but in the other six the pruritus was characteristic of $\mathrm{HD}$ in not being associated with cutaneous lesions.

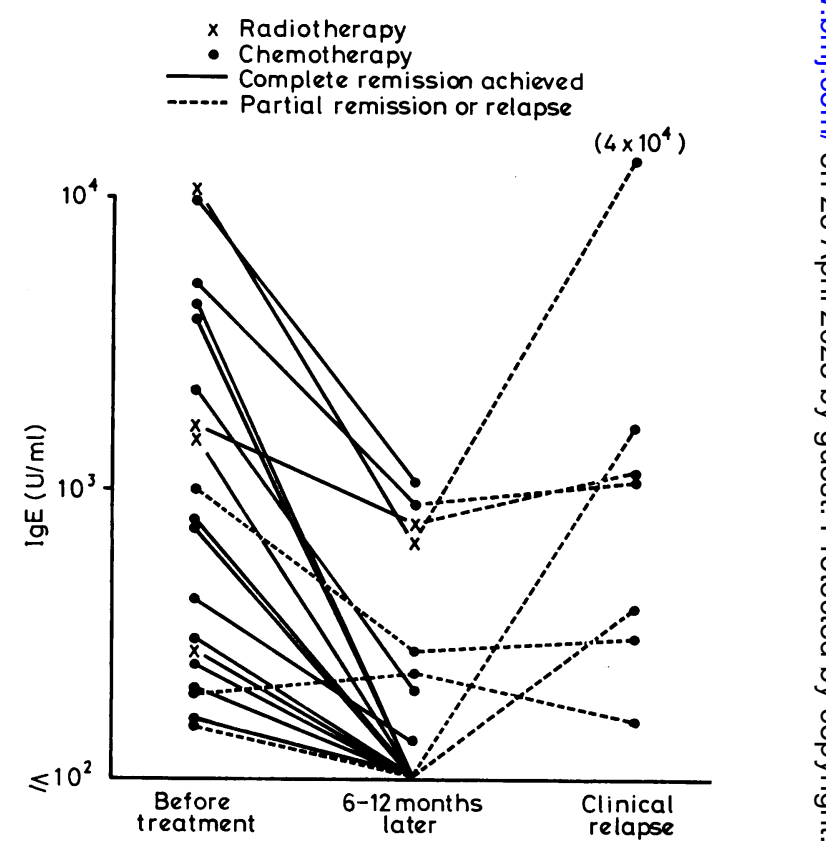

FIG 1-Effect of treatment for HD on high IgE concentrations in non-atopic patients. 
EFFECT OF TREATMENT ON IgE CONCENTRATIONS

Non-atopic patients-Nineteen of the non-atopic patients with HD and high IgE concentrations were followed up for over a year. Noticeable falls in serum IgE concentrations occurred after treatment of $\mathrm{HD}$ in almost all cases (see fig 1), the GM IgE concentration falling from $694 \mathrm{U} / \mathrm{ml}$ before treatment to $81 \mathrm{U} / \mathrm{ml}$ after treatment $(\mathrm{P}<$ 0.0005 , paired Student's $t$ test). In over half of these patients the IgE concentration was in the normal range after treatment and remained so except when HD relapsed. Relapse or persistence of active disease despite treatment was accompanied by relapse or persistence of high concentrations (fig 1). There was no significant change in IgE concentration among patients with $H D$ when the initial values had been in the normal range.

Atopic patients-Treatment of HD had no significant lasting effect on IgE concentrations in atopic patients (fig 2). Pretreatment (GM

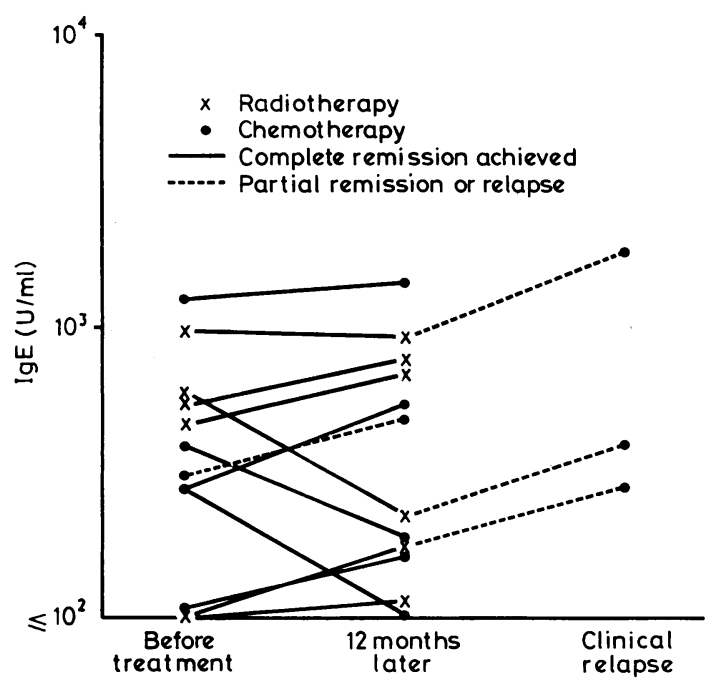

FIG 2-Effect of treatment for $\mathrm{HD}$ on $\mathrm{IgE}$ concentrations in atopic patients.

$283 \mathrm{U} / \mathrm{ml}$ ) and post-treatment (GM $321 \mathrm{U} / \mathrm{ml}$ ) samples were taken 12 months apart to compensate for the seasonal variation of serum IgE concentrations seen in atopic patients. When concentrations were measured during treatment, however, chemotherapy differed from radiotherapy in causing a progressive fall with each cycle of treatment, although within a few months of completing treatment the serum $\mathrm{IgE}$ concentration returned to near its previous value. Since cyclical quadruple chemotherapy is completed after six to eight months, our paired samples 12 months apart did not reflect this temporary fall in concentration.

\section{Discussion}

These results show that high IgE concentrations occur in HD but not in other types of lymphoma, in which even atopic patients have lower IgE concentrations than expected. In the group with $\mathrm{HD}$, atopic patients differed clinically from nonatopic patients with high $\mathrm{IgE}$ concentrations: the atopic patients were mostly asymptomatic, and treatment had only a transitory or negligible effect on the IgE concentration. This is surprising when the powerful immunosuppressive effect of treatment is considered and reinforces the original assumption that the increased serum IgE concentrations in atopic patients represent a continuing antibody response to common allergens not associated with HD.

In contrast, increased serum IgE concentrations in non-atopic patients with HD were most pronounced in symptomatic patients, particularly those with nodular sclerosis. In non-atopic patients high concentrations fell with treatment, returning to normal in most of those attaining complete remission and increasing again only with clinical relapse. There were no evident manifestations of type I allergy in this non-atopic group. Pruritus in patients with HD differs from that in patients with atopic eczema by being associated with no cutaneous lesions apart from those induced by scratching. It is difficult to conceive how either pruritus or histological changes can be caused directly by IgE-mediated events. Possibly, however, the eosinophil infiltration seen in tissues affected by HD ensues from IgE interactions. Normally there is a powerful cell-mediated suppression of IgE production, ${ }^{18}$ and in view of the defects of cellmediated immunity seen in $\mathrm{HD}$ it has been suggested that a deficiency of suppressor cells accounts for the increased serum IgE concentration. ${ }^{10}$ Our findings cannot easily be reconciled with this interpretation: why do certain histological types show a deficiency of suppressor cells and others, particularly the lymphocyte-depleted type, not show it? Suppressor cells are sensitive to irradiation and chemical immunosuppression, both of which lead to the continuation and augmentation of a normally suppressed IgE response, ${ }^{18}$ yet radiotherapy or chemotherapy in HD has the opposite effect.

The IgE response seen in the nodular sclerosis and mixed cellularity subtypes may be a stage in host defence intermediate between the abundant cell-mediated response seen in the lymphocyte-predominant type of HD and the feeble cellular response seen in the lymphocyte-depleted type. This IgE response could be protective in two ways-either because the $\mathrm{IgE}$ is specifically anti-HD or because it reflects a vigorous underlying cellular response with an adjuvant effect on IgE production. IgE has not been found on the surface of the abnormal cells in HD tissue, so if IgE is directed at HDassociated antigens these are not apparent at the cell surface. The alternative explanation of the adjuvant effect has its precedent in other diseases, for helminthic parasites stimulate IgE production, only part of which is directed at helminthic antigens, ${ }^{19}$ and simultaneously Bordetella pertussis depresses cellmediated immunity while stimulating IgE production. ${ }^{20}$ The effects of $B$ pertussis are particularly interesting because they mirror the immunological abnormalities seen in HD, understanding of which would allow better use of immunotherapeutic measures in this disease.

Particular thanks are due to Dr S J Barnes, whose help was invaluable at the start of this study. We also thank Dr D R Turner for reviewing slides not classified originally by the Rye method, and $\mathrm{Mr}$ F House for advice on statistical analysis. We are grateful to Professor J R Trounce; the oncology group of the department of radiotherapy and oncology at Guy's; and Dr M Minton and the haematology department at the London Hospital, for allowing us to study their patients. This study was supported by a grant from the Cancer Research Campaign.

Requests for reprints should be sent to P L Amlot.

\section{References}

${ }^{1}$ Fisherman, E W, fournal of Allergy, 1960, 31, 74.

2 Mackay, W D, British fournal of Cancer, 1966, 20, 434.

${ }^{3}$ Ure, D M J, Scottish Medical fournal, 1969, 14, 51.

${ }^{4}$ McKee, W D. Arnold, C A, and Perlman, M D, fournal of Allergy, 1967, 39, 294.

5 McCormick, D P, et al, Cancer, 1971, 27, 93.

${ }^{6}$ Dworin, M, Diamond, H D, and Craver, L F, Cancer, 1955, 8, 128.

7 Johansson, S G O, Lancet, 1967, 2, 951.

${ }^{8}$ McI aughlan, P, and Stanworth, D R, Lancet, 1975, 1, 64.

9 Winters, W D, and Heiner, D C, Fournal of Allergy, 1976, 57, 181.

${ }^{10}$ Waldmann, T A, et al, 7ournal of Immunology, 1974, 113, 379.

11 Steinberg, P, et al, fournal of Allergy, 1976, 57, 255.

12 Carbone, P P, et al, Cancer Research, 1971, 31, 1860.

${ }_{13}$ Lukes, R J, et al, Cancer Research, 1966, 26, 1311

14 Kaplan, H S, Cancer, 1966, 19, 356.

${ }_{15}$ De Vita, V T, Serpick, A, and Carbone, P P, Annals of Internal Medicine, $1970,73,881$.

${ }_{16}^{16}$ Nye, L, et al, Clinical Allergy, 1975, 1, 13.

17 Dunnett, C W, Biometrics, 1964, 20, 482.

18 Tada, T, Progress in Allergy, 1975, 19, 122.

19 Jarrett, E E E, and Stewart, D C, Immunology, 1972, 23, 749.

20 Ochiai, T, et al, International Archives of Allergy, 1972, 43, 196.

(Accepted 29 November 1977) 